A - preparing concepts

$\mathrm{B}$ - formulating methods

$\mathrm{C}$ - conducting research

$\mathrm{D}$ - processing results

E - interpretation and conclusions

$\mathrm{F}$ - editing the final version

Received: 2019-09-16

Accepted: 2020-01-07

Published: 2020-01-19

\section{Accessibility of gynaecology consultation rooms in Poland for individuals using wheelchairs in the opinion of women with physical disability}

\author{
Marta CichońA-E* (D), Paulina Aleksander-Szymanowicz ${ }^{A-E}$ (D), \\ Aneta Bac ${ }^{A, E, F}$ (D)
}

Faculty of Rehabilitation, Department of Occupational Therapy, Bronislaw Czech University of Physical Education in Cracow, Poland

*Correspondence: Marta Cichoń; Grota Roweckiego 41/20, 30-348, Cracow, Poland; e-mail: martacichon1@o2.pl

\begin{abstract}
Introduction: Little is known about the quality of adaptations of medical facilities that enable access to comprehensive gynaecological care for women with motor disability. The purpose of the study was to gather opinions of women using wheelchairs on the subject concerning the degree of adaptation of gynaecological offices for their needs.

Material and methods: The study group included 120 women with motor disability, moving with use of a wheelchair. The most common causes of disability of the studied women were: spinal cord injury (31.7\%) and cerebral palsy (29.2\%). The study was conducted with use of an original survey questionnaire consisting of 20 questions on the subject matter and 6 questions about respondent's particulars.

Results: The study has shown that $20 \%$ of women have never visited a gynaecologist and $66.7 \%$ of them indicated a difficulty to find an appropriately adapted doctor's office to be the cause of this situation. In a $0-5$ scale, the women who had gynaecological visits most commonly rated the adjustment of gynaecology consultation rooms in their places of residence as 0 ( $40 \%$ of women). $75 \%$ of women answered that accessibility of the gynaecology consultation rooms affects the frequency of their visits at a gynaecologist.

Conclusions: Based on the studied group of women, difficult access to gynaecology consultation rooms adapted to the needs of women on wheelchairs was found. Modification of the environment by removal of the most common barriers and creation of an accessible environment is important for appropriate gynaecological prophylaxis in women using wheelchairs.
\end{abstract}

Keywords: motor disability, gynaecology, occupational therapy, environmental ergonomics

\section{Introduction}

Accessibility of health is indispensable to provide relevant care for people with disability, however due to the existing barriers the disabled may encounter much bigger difficulties in the access to the routine medical prevention than the healthy ones. As a result, people with disability who require medical care (frequently unrelated to their disability) may give up seeking of a relevant help due to environmental obstacles that they encounter in medical facilities or doctors' offices. Thus, it is important to identify the types of obstacles,

This is an Open Access journal, all articles are distributed under the terms of the Creative Commons Attribution-NonCommercial-ShareAlike 4.0 International (CC BY-NC-SA 4.0). License (http://creativecommons. org/licenses/by-nc-sa/4.0/). 
to make patient's way to the doctors more convenient and to improve the access to medical services of appropriate quality [1].

According to the American Occupational Therapy Association (AOTA) the occupational therapist plays a very important role in the modification of the environment [2]. One of the principal actions here is the assessment of the space, identification of the problems and selection of the relevant solutions that would allow for creation of a barrierless environment [3, 4]. A therapeutic intervention should provide safety for the patient which means that the occupational therapist must eliminate the risk of falls and body injuries through appropriate furniture arrangement, provision of an antislip floor surface or selection of appropriate supportive equipment [5].

In the Polish literature, there are no comprehensive articles on the adjustment of doctor's offices for people with motor disabilities therefore, the purpose of this work was to assess accessibility of gynaecological offices in Poland for the patients on wheelchairs, in the opinion of women with physical disabilities. Because we believe that one of the activities of an occupational therapist should be to help create barrier-free medical offices for people with physical disabilities, we hope that the results of our research will identify areas of intervention for occupational therapists.

\section{Material and methods}

The study included randomly selected 120 women with their place of residence in Poland. It was approved by the Ethics Committee (L.dz.OIL/KBL/29/2018). The only inclusion criterion was motor disability with the need to use a wheelchair, without any concomitant intellectual disability. Average age in the studied group of women was 32 years. The youngest respondent was 18 years old and the oldest one -67 years old. The majority of the questioned women fell into the age range of 26-35 years ( 52 persons). Thirty nine respondents were younger than 25 years of age. There were 20 women in the 36-49 years' age group. The smallest group $(n=9)$ included women aged 50 years and older (Fig. 1).

Distribution of the study group by residence was almost balanced. The most commonly declared place of residence was a rural area (26 women) or a city with more than 500000 inhabitants (22 women). Twenty women lived in a city with 10000 to 50000 inhabitants and 19 women - in a city with less than 10000 inhabitants. The other groups were as follows: Seventeen women lived in a city with 100000 to 500000 inhabitants and 16 women lived in a city with 50000 to 100000 inhabitants (Fig. 2).

The most common cause of disability was an injury of the spinal cord that was noted in 38 women. The second most common cause was cerebral palsy $(n=35)$. The third group $(n=25)$ with respect to frequency included other types of disability (e.g. congenital bone fragility, myelomeningocele). The other causes of disability of the studied women were as follows: muscular dystrophy $(n=14)$, multiple sclerosis $(n=5)$ and injury or loss of the extremities were noted in 3 women (Fig. 3).

In this work, an own author's survey questionnaire was used that consisted of 26 questions and was available in two versions: electronic and paper ones. The first part consisted of 20 questions concerning gynaecological offices. The second part included 6 questions on respondent's particulars. The questionnaire included questions of the closed and semi-open categories. They were single-choice and multiple-choice questions. The

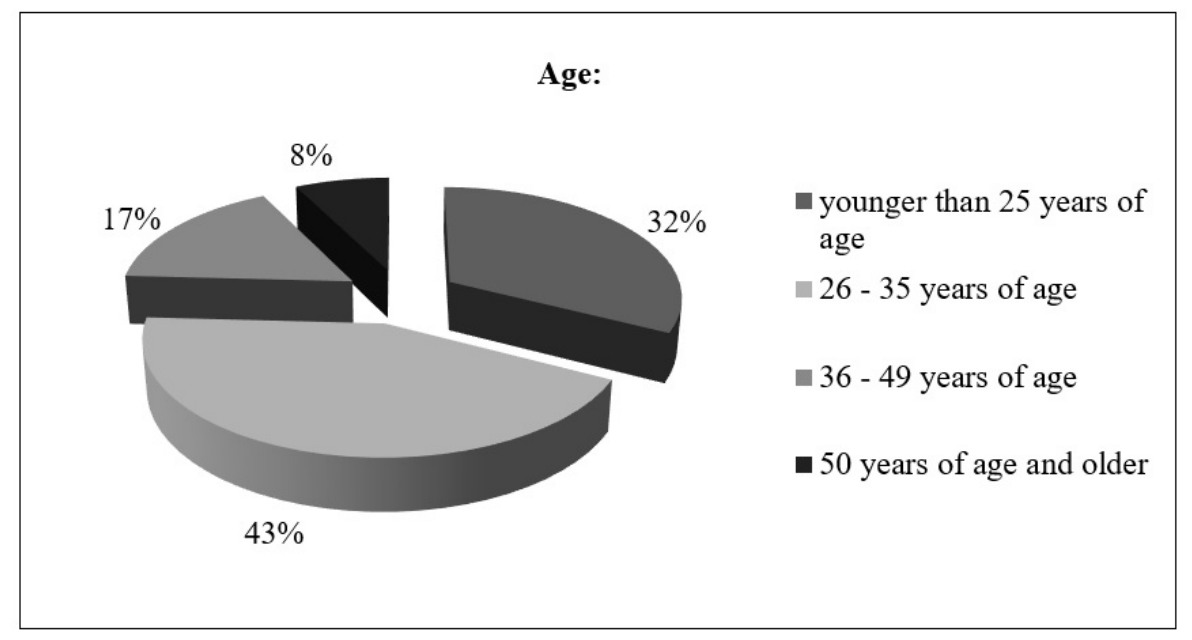

Fig. 1. Characteristics of the group in terms of age 


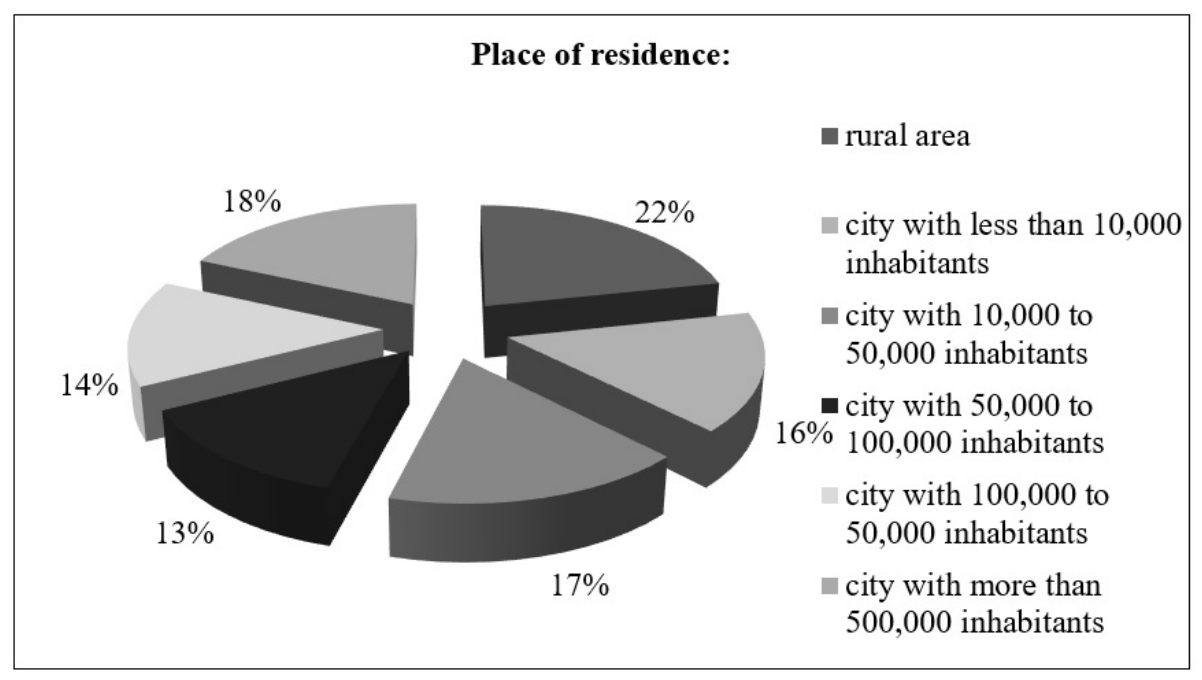

Fig. 2. Characteristics of the group in terms of place of residence

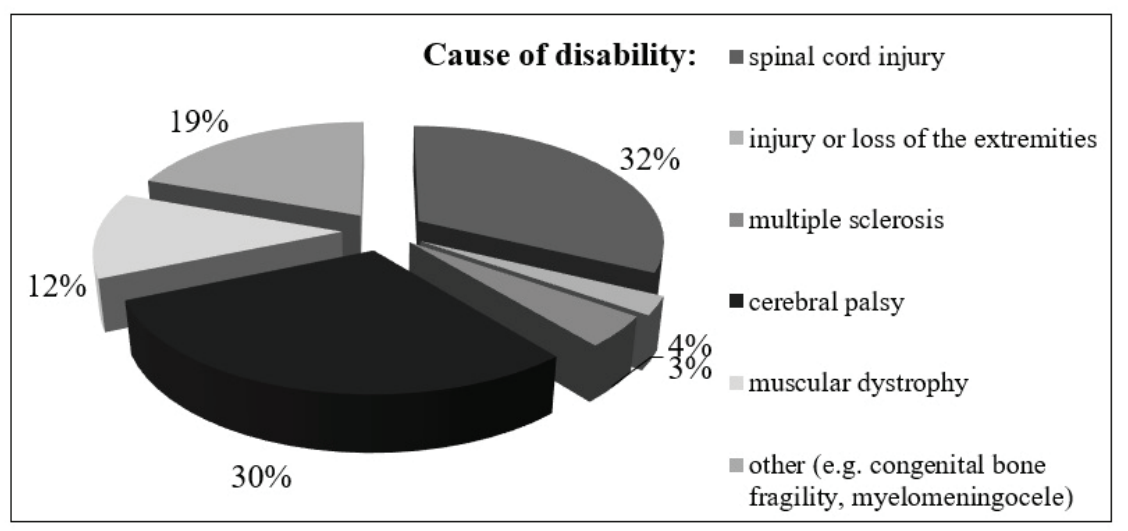

Fig. 3. Characteristics of the group in terms of disability

questions were created based on women's experience related to gynaecological visits, which were collected mainly through social media. Questionnaire completion was voluntary and anonymous. The results were analysed with use of the Microsoft Excel 2010 software, version 14.0.7181.5000 (32-bit). To verify the assumed hypotheses, statistical calculations were done that examined the relationships between selected data with use of the Pearsons chi-square test. All research activities were approved by the Bioethics Committee. All participants were informed that the participation of the study is voluntary and anonymous.

\section{Results}

All examined women $(n=120,100 \%)$ declared that medical prevention is of high importance to them. The study showed that the majority of the questioned women $(\mathrm{n}=41,34.2 \%)$ visit a gynaecologist more frequently than once a year, 32 women (26.7\%) less frequently than once a year, and 23 women (19.1\%) less frequently than every 3 years. The other 24 women (20\%) never visited a gynaecologist.

Among women who never visited a gynaecologist, the most frequently declared cause was the difficulty to find an gynaecological office with appropriate adjustments for women on wheelchairs (16 women, 66.7\%). Six women (25\%) felt no need to seek gynaecological care and 2 women (8.3\%) were never consulted by a gynaecologist for other reasons (e.g. the doctor refused to admit the patient). Among the studied women attending a gynaecologist (96 respondents, 80\%), most frequently declared cause of gynaecological visits was preventive examination only $(n=64,66.7 \%)$, and the second most common cause were health problems only $(\mathrm{n}=22,23 \%)$. The majority of the respondents visits the gynaecological offices that provide services within the National Health Fund (47 women 48.9\%). 27 women $(28.1 \%)$ attends private gynaecological practices and 22 women (23\%) use both National Health Fund and private offices. 


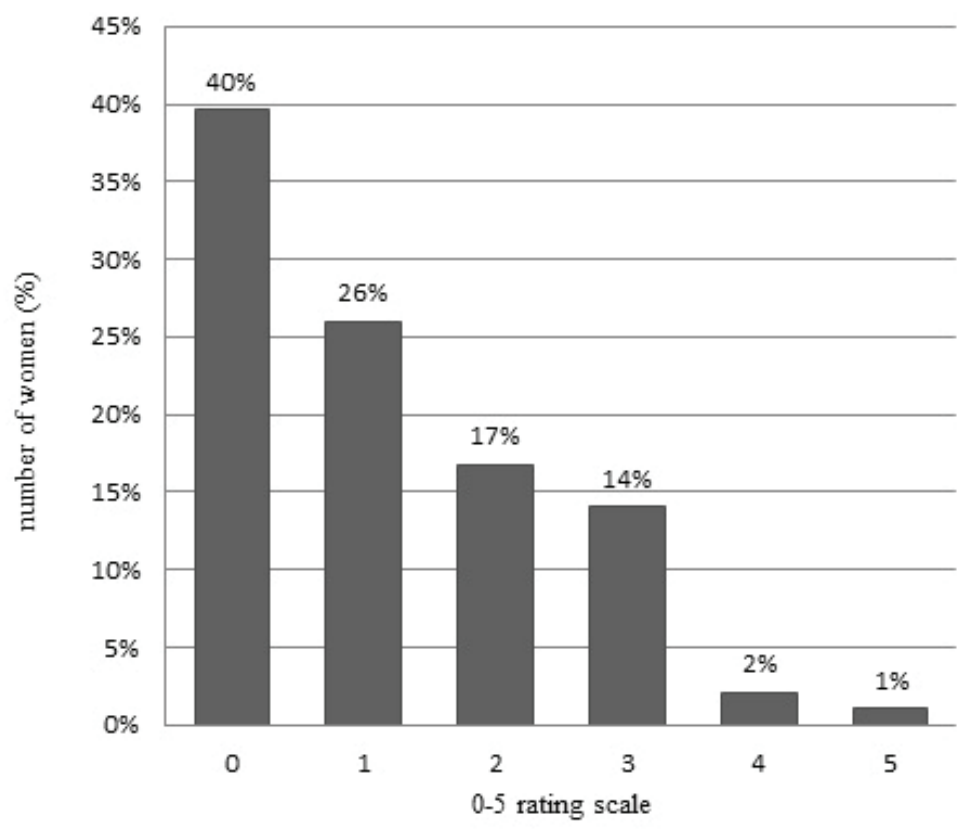

Fig. 4. Availability assessment of gynaecological examination rooms in Poland in patients place of living

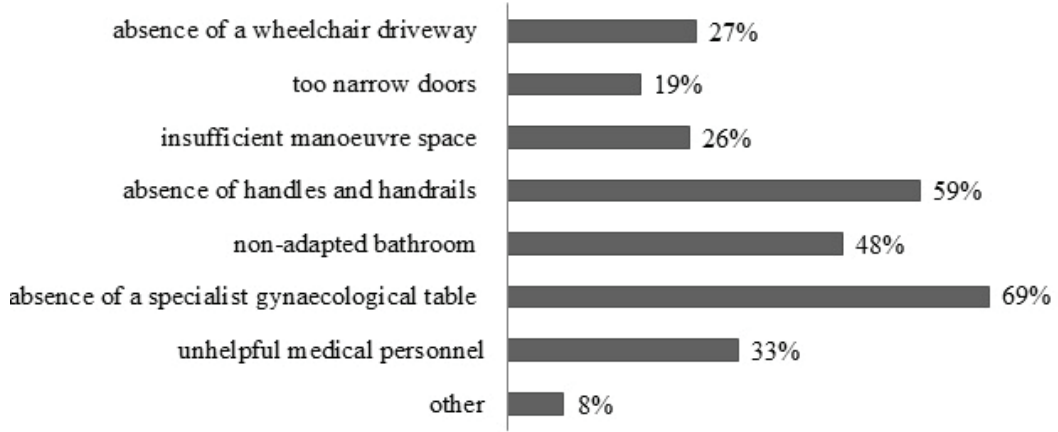

Fig. 5. Barriers for women on wheelchair appearing in gynaecological offices in Poland

The study showed that on a $0-5$ rating scale, where 0 means the absence of any amenities and 5 means full adapted gynaecological office, the most women rates the accessibility of gynaecological offices in their living place to the women using wheelchairs at 0 ( 38 women). The second most frequent rating is 1 ( 25 women), and the third most frequent rating is 2 (16 women). 14 women rated the accessibility at 3 . The rating 4 was given by 2 women and 1 woman rated the accessibility of the gynaecological offices in her place of living at 5 (Fig. 4.).

The majority of the respondents $(n=65,67.7 \%)$ visiting a gynaecologist need help of an assistant (e.g. of a family member) during the visit.

The results of the study showed that the most common barriers for women on wheelchairs who need gynaecological consultation include the following: absence of a specialist gynaecological table (66 women), absence of handles and handrails (56 women) and non-adapted bathroom (46 women). The other barriers include the following: unhelpful medical personnel (31 women), absence of a wheelchair driveway (26 women), insufficient manoeuvre space ( 25 women), too narrow doors (18 women) and other, e.g. absence of a lift ( 8 women). These results were obtained based on the answers of 95 respondents because one woman visiting a gynaecologist rated the gynaecological offices at 5 which indicated the absence of any barriers in her opinion (Fig. 5).

The study showed that the accessibility of gynaecological offices for women on wheelchairs affect the frequency of gynaecological visits in the majority of the interviewed women $(\mathrm{n}=90,75 \%)$.

Almost one half of the interviewed women ( $\mathrm{n}=54$, $45 \%$ ) encountered discrimination of persons with physical disabilities by medical personnel. 
Tab. 1. Relationship between the frequency of gynaecological visits and the size of the place of residence, educational level, severity and duration of disability of the respondent

\begin{tabular}{lccc}
\hline Variable & \multicolumn{3}{c}{ Frequency of gynaecological visits } \\
\hline & $\mathrm{x}^{2}$ & $\mathrm{df}$ & $\mathrm{p}$ \\
\hline Size of the city of residence & 19.44 & 15 & 0.194 \\
\hline Educational level & 15.81 & 9 & 0.071 \\
\hline Severity of disability & 8.64 & 6 & 0.195 \\
\hline Duration of disability & 80.73 & 3 & $<0.001$ \\
\hline
\end{tabular}

Twenty seven of the interviewed women $(22.5 \%)$ admitted that they were refused a visit in the gynaecological office due to their motor disability. For the majority of the interviewed women $(n=67,55.8 \%)$ their motor disability constitutes a mental barrier for gynaecological consultation. Statistical significance was found in the analysis of the relationship between the frequency of gynaecological visits and the duration of disability (acquired vs. congenital) $(p<0.001)$. The women with congenital motor disability visit the gynaecologist less frequently than these with acquired disability (Tab. 1).

\section{Discussion}

The most recent results of the National Census of the year 2014 presented by Statistics Poland show that the population of disabled persons in Poland counts $4,700,000$ people which is $12.2 \%$ of the entire Polish population. Injuries and diseases of the motor system are the most common cause of disability (65\% in women and $52 \%$ in men) and represent more than a half of all disabilities in Poland [6]. Absence of gynaecological offices adapted to women using wheelchair and their irregular and rare gynaecological visits, being the consequence of this absence, translate into a low quality of preventive actions. As a consequence, the chances to detect any possible pathological lesions at an early stage decrease which significantly worsens the prognosis [7]. Taking into consideration the above mentioned number of women with motor disabilities in Poland, a significant percentage of Polish women is at risk of receiving optimal healthcare because of the absence of appropriately adapted gynaecological offices. Poland is a country with high morbidity and mortality rates due to genital system malignancies which is highly affected by low awareness, among others [8]. To underline that presence of barriers diminishing accessibility of gynaecological offices has a predominant effect on the frequency of visits at a gynaecologist among women using wheelchairs, our own results should be confronted with the report on gynaecological prophylaxis in Poland. In the population of healthy women examined in the year 2013 in Poland, 1550 women ( $74 \%$ of respondents) declared regular visits at a gynaecologist, $17.4 \%$ of the respondents indicated sporadic visits and $8.3 \%$ of them never consulted a gynaecologist [9]. In the light of recommendations on gynaecological prophylaxis [10] the above data are not satisfactory however they clearly differ from the information collected in our own study that showed that as many as $20 \%$ of the respondents never visited a gynaecologist. Among the women examined in the year 2013, the most common causes of this situation were as follows: embarrassment before the first visit and shortage of time [11] whereas the respondents using wheelchairs indicated the difficulties in finding of an appropriately adapted gynaecological office as the most common reason. It is also of note that $100 \%$ of the interviewed women in our study confirmed that health prevention is important for them. A vast majority of women (90 respondents, $75 \%$ ) admitted also that the quality of gynaecological office adaptation to their needs affects the frequency of their gynaecological visits.

Little is known about the quality of medical facilities' adaptation in Poland, as the available scientific literature contains only scarce reports. In an assessment of public outpatient clinics in Kraków, Wąsowska [12] showed significant shortcomings in adaptation of the medical facilities to the needs of people on wheelchairs. As shown in her results, $25 \%$ of outpatient clinics with more than one floor have no wheelchair driveways or other amenities enabling to enter the building. Inside the building, stairways are the only way to get to the upper floors in $12 \%$ of the clinics. Only half of the toilets are adapted to the needs of the people on wheelchairs. Automatic doors are found in as little as $10 \%$ of the examined facilities. Similar results were obtained one year later by Nawalna, Baran \& Nowak [13], who assessed 44 Primary Care facilities in Kraków. The authors confirmed that almost $80 \%$ of the clinics have amenities allowing entrance to the building as well as elevators and lifts enabling movement between the floors inside 
the building and $65 \%$ of the toilets were designed and equipped in a way that has made them accessible to the disabled. Measurements of the width of the corridors and doors with regard to the needs of the persons on wheelchairs showed that $68 \%$ of the corridors and $79 \%$ of the doors allow for unrestrained movement within the building. Twelve percent of the assessed institutions had automatic door [13].

Only one study on accessibility of gynaecological offices for women with motor disability was conducted previously in Poland. Radomski, Jarząbek-Bielecka, Sowińska-Przepiera \& Milewczyk [14], based on a study of a group of 30 women using wheelchairs reported that $37 \%$ of the respondents did not visit a gynaecologist at all. According to this author, the most common reason of this fact $(76 \%)$ was the absence of facilities adapted to the needs of this group of patients. Additionally, 55\% of women found that medical personnel had no adequate knowledge about the gynaecological needs of women on wheelchairs and $37 \%$ of women experienced insensibility of health care professionals toward their problems [14]. The data obtained in our study confirm the above results as the opinions of my respondents also pointed to insensibility and discrimination that they experienced from the healthcare professionals (e.g. the doctors refused to admit the patients because of their disability).

When discussing the issue of the barriers, the specificity of the gynaecological examination, being one of the most intimate medical procedures, should be taken into account and it is very important that the relevant medical personnel treated the patient with empathy and respect [15]. To make it real, the medical personnel must be aware of the fact that a woman with motor disability should be examined with the same regularity as a healthy one. Motor disability does not mean an absent need for gynaecological care, absent sexual life or absent willingness to have a child. Our study allowed to obtain information about suitability of the gynaecological offices to the needs of disabled patients in Poland, as assessed by women moving on wheelchairs. Based on the collected data the most common barriers and obstacles were determined. Also some deficits in the awareness of the needs of the women on wheelchairs among the medical personnel were shown. Presentation of the effect of gyneaecological offices accessibility on the frequency of patient's visits and comparison of the collected results with foreign studies enabled to prove that there is a necessity to improve the situation in Poland. It is worth to stress once more that adjusting of gynaecological offices to the needs of disabled patients is the starting point of appropriate healthcare for this group of patients. Due to the low quality of gynaecological care for women using wheelchairs we believe that occupational therapists should help in creating barrierless medical offices for people with physical disabilities, because one of the principal actions of the occupational therapist is the assessment of the space, identification of the problems and selection of the relevant solutions that would allow for creation of a barrierless environment.

However occupational therapist's interventions will not provide effectiveness if no one knows how to help women using wheelchair. The research have shown that often overlooked component is adequate training of medical staff. Individuals using wheelchairs are not all the same - they may use mobility devices of different types, transfer in different ways, and have varying levels of physical ability. It is important to training staff to properly assist with transfers and lifting. Medical staff should know how ask what assistance, if any, is needed and how to provide it, which will go a long way toward providing safe and accessible health care for people with mobility disabilities. Staff must be also constantly trained on its proper use particular medical equipment.

The efforts to assure appropriate quality are a prerequisite here as any negligence resulting from the existing barriers may put at risk the most important values: human health and life.

\section{Conclusions}

1. Based on the opinions of the studied women, difficult access to gynaecological offices adapted to the needs of women on wheelchairs was found.

2. In the opinion of the questioned women, gynaecological offices have many barriers that prevent persons on wheelchairs from receiving medical services. The most common barriers include the following: the absence of an adapted gynaecological table, absence of handles and handrails in the doctor's office and non-adapted bathroom.

3. In the opinion of the examined persons, difficult access of women on wheelchairs to medical offices plays an important role in the frequency of gynaecological visits.

4. Such factors as the size of the city of residence, age and educational level of the respondents have no effect on the frequency of gynaecological visits. Among the studied group of women, the regularity of gynaecological visits most commonly depends on the quality and accessibility of the doctor's office.

\section{Funding:}

This research received no external funding.

\section{Conflicts of interest}

The authors declare no conflict of interest. 


\section{References}

1. Jha A, Patrick DL, MacLehose RF, Jason N, Leighton C. Dissatisfaction with medical services among medicare beneficiaries with disabilities. Arch Phys Med Rehabil. 2002; 83(10): 1335.

2. aota.org [Internet]. American Occupational Therapy Association. Occupational Therapy Practitioners \& Ergonomics; [cited 2017 Jan 25]Available from: http:// www.aota.org/About-Occupational-Therapy/Professionals/WI/Ergonomics.aspx.

3. Jelinkova J, Krivosikova M, Sajtarova L. Ergoterapie. Pragaue: Portal; 2009.

4. Svestkova O, Svecena K, Formankova P. Czy terapia zajęciowa jest istotna $\mathrm{w}$ procesie rehabilitacji?. Niepełnosprawność - zagadnienia, problemy, rozwiązania. 2014; 12(3): 92.

5. Aleksander-Szymanowicz P. Terapia zajęciowa w dysfunkcjach narządu ruchu. In Bac A, editor. Terapia zajęciowa, Warsaw: Wyd. Lek. PZW; 2016. p. 76.

6. stat.gov.pl [Internet]. Główny Urząd Statystyczny; [cited 2017 Feb 24] Available from: http:/www.stat. gov.pl/obszary-tematyczne/zdrowie/zdrowie/stanzdrowia-ludnosci-polski-w-2014-r-,6,6.html.

7. Mele N, Archer J, Pusch BD. Access to breast cancer screening services for women with disabilities. J Obst Gyn Neo. 2005; 234(4): 453-64.
8. onkologia.org.pl [Internet]. National Cancer Registry; [cited 2017 Jan 29 ]Available from: http://onkologia. org.pl/wp-content/uploads/Nowotwory_2015.pdf

9. ponton.org [Internet]. Ponton Group of Sex Education; [cited 2017 Feb 09] Available from: http://ponton.org. $\mathrm{pl} /$ sites/ponton/files/bezpieczny_fotel_raport2014.pdf

10. Blanchard AK, Goodall P. Preventive Care in Women's Health. Obstetrics and Gynecology Clinics of North America. 2016; 43(2): 165-80.

11. Wąsowska I. Czy krakowskie przychodnie są przyjazne osobom niepełnosprawnym?. Medycyna Środowiskowa. 2014; 17(4): 66-7.

12. Nawalana A, Baran M, Nowak A. Problemy i bariery osób niepełnosprawnych fizycznie. Probl Pielęg. 2014; 22(2): 180-1.

13. Radomski D, Jarząbek-Bielecka G, Sowińska-Przepiera E, Milewczyk P. Problem opieki ginekologicznej nad dziewczętami i kobietami niepełnosprawnymi. Ginekol Prakt. 2010; 05(2): 36-42.

14. Jarząbek G, Radomski D. Specyfika opieki ginekologicznej i seksuologicznej nad kobietami niepełnosprawnymi w okresie pomenopauzalnym z uwzględnieniem aspektów etycznych. Przegl Menopauzalny. $2011 ; 1: 65$.

15. Fiedorowicz A. Niełatwe kobiece sprawy. Integracja. 2014; 128(6): 27-8. 